\title{
Optimizing cofactor availability for the production of recombinant heme peroxidase in Pichia pastoris
}

\author{
Florian W Krainer ${ }^{1 \dagger}$, Simona Capone ${ }^{2 \dagger}$, Martin Jäger², Thomas Vogl ${ }^{1}$, Michaela Gerstmann ${ }^{1}$, Anton Glieder ${ }^{1}$, \\ Christoph Herwig ${ }^{2}$ and Oliver Spadiut $2^{2^{*}}$
}

\begin{abstract}
Background: Insufficient incorporation of heme is considered a central impeding cause in the recombinant production of active heme proteins. Currently, two approaches are commonly taken to overcome this bottleneck; metabolic engineering of the heme biosynthesis pathway in the host organism to enhance intracellular heme production, and supplementation of the growth medium with the desired cofactor or precursors thereof to allow saturation of recombinantly produced apo-forms of the target protein. In this study, we investigated the effect of both, pathway engineering and medium supplementation, to optimize the recombinant production of the heme protein horseradish peroxidase in the yeast Pichia pastoris.
\end{abstract}

Results: In contrast to studies with other hosts, co-overexpression of genes of the endogenous heme biosynthesis pathway did not improve the recombinant production of active heme protein. However, medium supplementation with hemin proved to be an efficient strategy to increase the yield of active enzyme, whereas supplementation with the commonly used precursor 5-aminolevulinic acid did not affect target protein yield.

Conclusions: The yield of active recombinant heme peroxidase from $P$. pastoris can be easily enhanced by supplementation of the cultivation medium with hemin. Thereby, secreted apo-species of the target protein are effectively saturated with cofactor, maximizing the yield of target enzyme activity.

Keywords: Pichia pastoris, Recombinant protein production, Plant peroxidase, Horseradish peroxidase, Metabolic engineering, Cofactor, Heme, Heme biosynthesis, Apo-protein

\section{Background}

The methylotrophic yeast Pichia pastoris is a valuable host for the recombinant production of complex proteins. A considerable number of these proteins requires cofactors, amongst others heme, to form active biocatalysts. Heme biosynthesis (Figure 1) is tightly regulated and highly conserved throughout evolution [1-3].

To deepen our understanding on pathway regulation and improve cofactor availability for recombinant heme proteins, metabolic engineering of the heme biosynthesis pathway has been performed in Aspergillus niger [4,5], Escherichia coli [6] and Saccharomyces cerevisiae [7-9]. Despite the high conservation of the heme biosynthesis

\footnotetext{
* Correspondence: oliver.spadiut@tuwien.ac.at

${ }^{+}$Equal contributors

${ }^{2}$ Vienna University of Technology, Institute of Chemical Engineering, Research Area Biochemical Engineering, Gumpendorfer Strasse 1a, 1060 Vienna, Austria

Full list of author information is available at the end of the article
}

pathway, distinct differences were found among the different species. In $E$. coli, formation of 5-aminolevulinic acid (ALA) by the HEM1-encoded ALA synthase was described as rate-limiting step [10], whereas in S. cerevisiae the HEM2- and HEM3-encoded porphobilinogen synthase and deaminase, respectively, were described as ratelimiting [7]. Based thereon, overexpression of HEM3 alone or in combination with HEM2 and HEM12 was described to be a valuable strategy to augment the production of recombinant heme proteins in S. cerevisiae $[9,11]$. Despite these promising results, there are some potential pitfalls connected to metabolic pathway engineering, such as the additional metabolic burden upon overexpression of multiple genes as well as an accumulation of free intracellular porphyrin intermediates which can lead to the formation of reactive oxygen species [12]. Thus, medium supplementation with iron, heme precursors or hemin (the ferric chloride species of heme) was assessed as alternative 


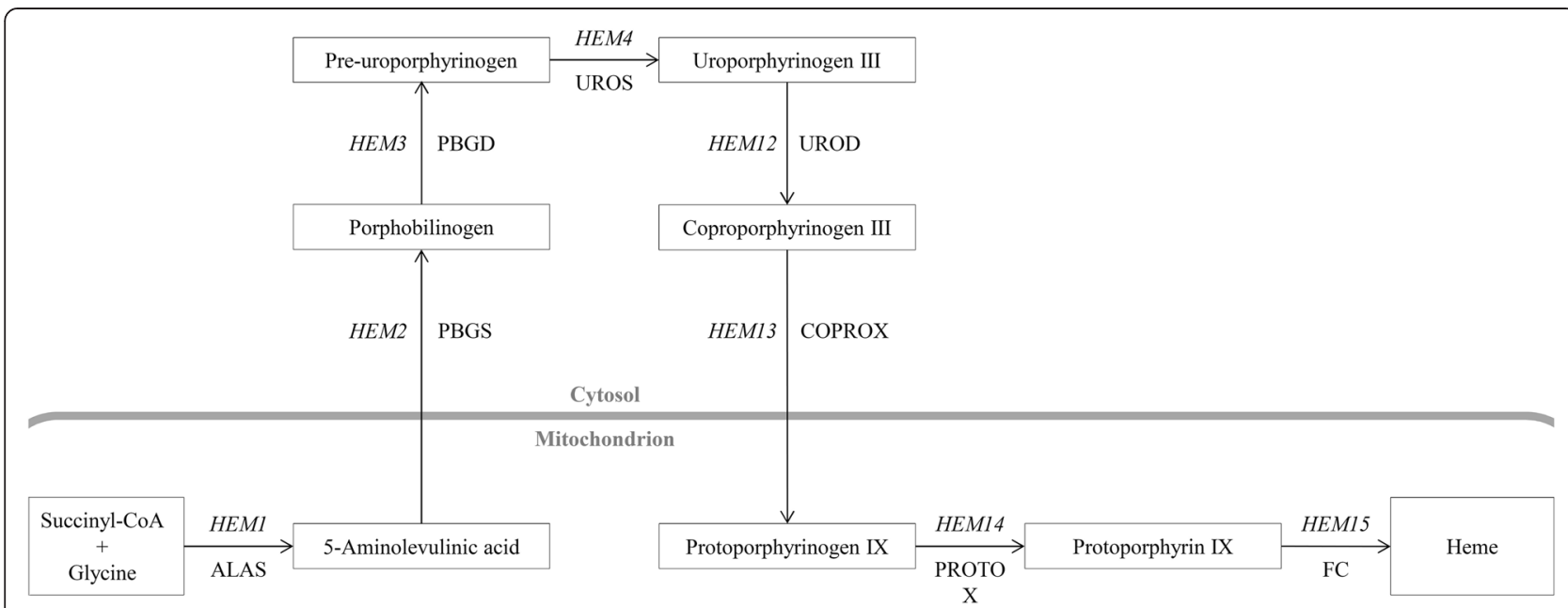

Figure 1 Scheme of the heme biosynthesis pathway. ALAS, 5-aminolevulinic acid synthase; PBGS, porphobilinogen synthase; PBGD, porphobilinogen deaminase; UROS, uroporphyrinogen III synthase; UROD, uroporphyrinogen III decarboxylase; COPROX, coproporphyrinogen III oxidase; PROTOX, protoporphyrinogen IX oxidase; FC, ferrochelatase.

strategy to effectively saturate recombinant apo-species of heme proteins [13-17].

In this study, we aimed at optimizing heme availability and thus boost the amount of recombinant active heme protein, namely horseradish peroxidase (HRP), in the yeast $P$. pastoris by evaluating pathway engineering and medium supplementation. In a systematic approach, we co-overexpressed HRP with genes of the endogenous heme biosynthesis pathway of $P$. pastoris, and assessed the effect of medium supplementation with iron, ALA and hemin on the yield of target enzyme activity.

\section{Results and discussion}

Heme biosynthesis pathway in Pichia pastoris

The heme biosynthesis pathway of several organisms has been described before and was found to be highly conserved [1-3]. Based on the HEM gene sequences from $S$. cerevisiae, we identified the corresponding homologs in the partially annotated genome of $P$. pastoris [18] in silico (Table 1). Sanger sequencing confirmed the correct nucleotide sequences of HEM1, HEM2, HEM3, HEM4, HEM12, HEM13 and HEM14. For HEM15, nucleotide 918 was $G$ in the GenBank database entries of the published genomes of $P$. pastoris strains CBS 7435 and GS155, but $\mathrm{T}$ in the Sanger-sequenced CBS 7435 P. pastoris strain used in the present study (Additional file 1). However, this single nucleotide polymorphism only resulted in a silent mutation and did not alter the amino acid sequence of the encoded protoheme ferro-lyase.

\section{Co-overexpression of HEM genes in microscale cultivations}

In a recent study it was shown that metabolic engineering of the heme biosynthesis pathway allowed higher yields of active recombinant heme protein in S. cerevisiae [11]. Thus, we co-overexpressed either of the eight involved

Table 1 In silico identification of HEM homologs in $P$. pastoris

\begin{tabular}{lllll}
\hline S. cerevisiae & P. pastoris & & & \\
Gene annotation & Gene annotation & Chromosome & COG annotation & $\begin{array}{c}\text { Sequence } \\
\text { identity [\%] }\end{array}$ \\
\hline HEM1 & HEM1 & II & 5-aminolevulinate synthase & 67.7 \\
HEM2 & HEM2 & IV & delta-aminolevulinic acid dehydratase & 75.3 \\
HEM3 & HEM3 & I & porphobilinogen deaminase & 54.0 \\
HEM4 & HEM4 & II & uroporphyrinogen-III synthase & 42.3 \\
HEM12 & n/a & III & uroporphyrinogen decarboxylase & 73.2 \\
HEM13 & HEM13 & III & coproporphyrinogen III oxidase & 65.5 \\
HEM14 & n/a & IV & protoporphyrinogen oxidase & 33.7 \\
HEM15 & $\mathrm{n} / \mathrm{a}$ & III & protoheme ferro-lyase (ferrochelatase) & 61.2 \\
\hline
\end{tabular}

Genes HEM12, HEM14 and HEM15 were not annotated (n/a) for P. pastoris CBS 7435. Their chromosomal position in the genome, eukaryotic cluster of orthologous groups (COG; [19]) annotations and identities of the encoded amino acid sequences from S. cerevisiae and $P$. pastoris are shown. 
HEM genes (Table 1) using the strong constitutive promoter PGAP [20] in a P. pastoris strain recombinantly producing the heme protein HRP. The screenings revealed trends of co-overexpressed HEM1 and HEM3 to be potentially beneficial for the production of active HRP (Figure 2). Surprisingly, there also seemed to be a negative trend upon co-overexpression of HEM4. We hypothesize, that HEM4 co-overexpression might have led to the accumulation of a cytotoxic intermediate, which increased intracellular stress and ultimately caused a disadvantageous production environment for HRP under the tested conditions. At this point, we did not follow up on the effects of HEM4 cooverexpression. Since co-overexpression of eGFP as negative control did not affect HRP productivity, the observed activity-enhancing trends seen for HEM1 and HEM3 were considered a consequence of the co-overexpressed HEM gene, although the standard deviation in these experiments was high. The high standard deviations in this screening (Figure 2) were caused by the transformant-totransformant variation typically observed for $P$. pastoris [21]. Even the transformation of a single gene results in transformants showing different expression strengths. The majority of the transformants shaping the landscape behaved similar but a few transformants showed either no expression or elevated levels, leading to high standard deviations. Supplementation of the cultivation medium with $1 \mathrm{mM} \mathrm{FeSO}_{4}$ to alleviate a potential iron limitation gave comparable results to non-supplemented medium and did not affect the observed trends upon HEM gene co-overexpression (data not shown).

In addition to strong constitutive co-overexpression of either HEM1 or HEM3 from PGAP, we also tested cooverexpression of these two genes from either $\mathrm{P} A O X 1$ or PCAT1. Both promoters are strongly methanol-inducible, however PCAT1 is already active in the absence of glucose or glycerol and then even further induced by addition of methanol, thereby allowing HEM co-overexpression already prior to, but also during HRP production [Vogl et al., manuscript in preparation]. In order to indirectly assess the general functionality and applicability of the employed co-overexpression construct, we measured fluorescence of the eGFP co-overexpression control transformants and found this co-overexpression partner to be successfully produced (Additional file 2). Thus, we considered the endogenous HEM co-overexpression partners to be co-overexpressed in a comparable fashion. Ultimately, PAOX1-regulated co-overexpressions of HEM1 and HEM3 with HRP were found most promising (Additional file 3) and the best performing strains were used for further characterizations.

Since the data from microscale cultivations indicated merely trends for potential beneficial effects of co-overexpressed HEM1 or HEM3, we aimed at obtaining more reliable data from controlled cultivations of the best performing strains in bioreactors. Prior to bioreactor cultivations, the strain producing HRP alone (hereafter called benchmark

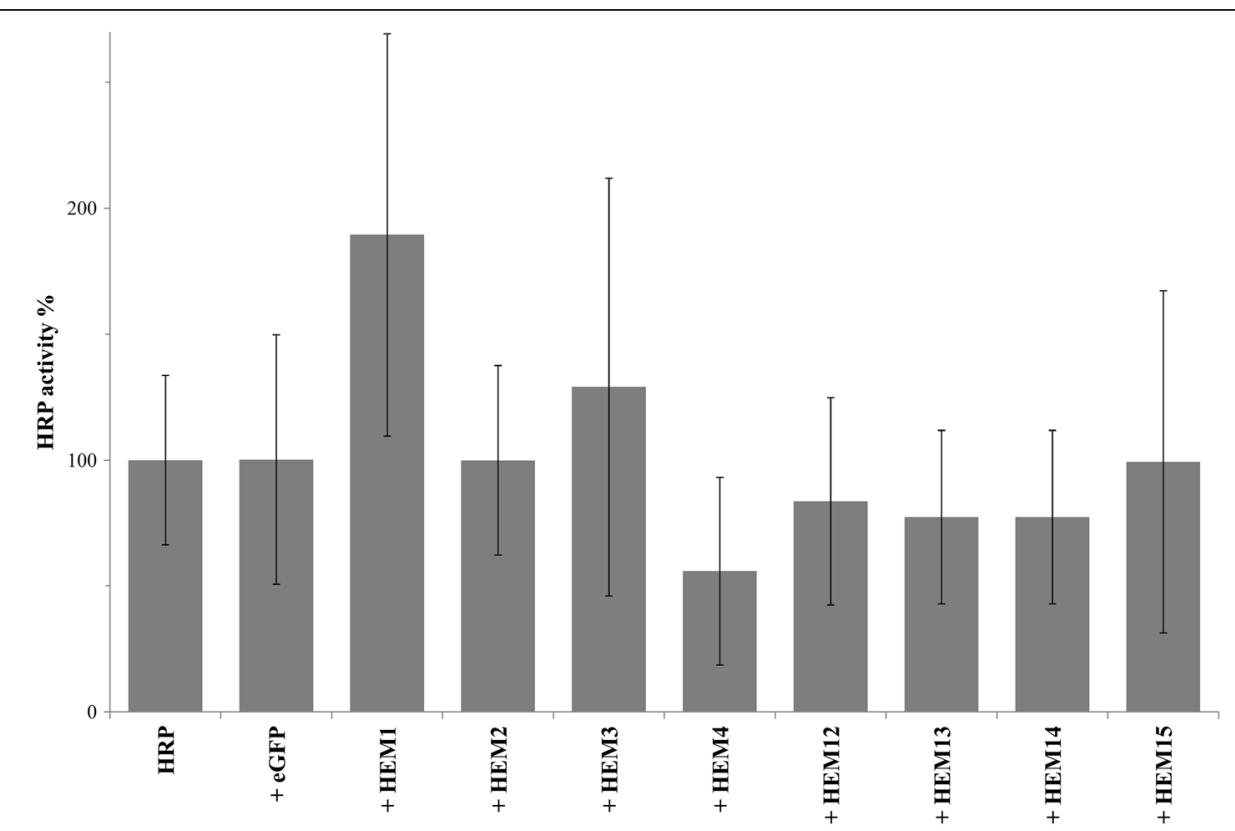

Figure 2 Co-overexpressions of HEM genes with HRP. HRP overexpression was regulated by PAOXI, co-overexpressions of eGFP and HEM were regulated by PGAP. Bars are average values of HRP production landscapes from microscale cultivations using $1 \mathrm{mM} \mathrm{FeSO}_{4}$-supplemented medium. Error bars are standard deviations from all measured clones of a landscape. Average activity from strains producing HRP alone was set to $100 \%$. 
strain) as well as the HEM1 and HEM3 co-overexpressing strains (hereafter called HEM1 and HEM3 strains) were characterized by quantitative real-time PCR as strains with single copy integration of the HRP gene. Since these strains contained the same HRP gene dosage, genomic rearrangement of HRP gene copy number upon transformation of a HEM co-overexpression construct was excluded and the strains were regarded comparable in terms of target gene dosage.

\section{Co-overexpression of HEM genes in bioreactor cultivations}

For physiological strain characterisation of the three yeast strains we employed a previously reported strategy of dynamic batch cultivations with methanol pulses [22-25]. The corresponding off-gas signals, specific uptake rates and yields are shown in Additional file 4. Physiological strain characteristic parameters of the three strains are summarized in Table 2. As shown in Table 2, C-balances for all cultivations closed to 1.0 indicating solid data quality. Apparently, the yeast strains were physiologically not impaired by co-overexpression of either HEM1 or HEM3 since adaptation time to methanol, yields and specific substrate uptake rates were comparable. However, cooverexpressing these genes did not boost the production of active HRP either. Whereas the benchmark and the HEM1 strain showed comparable production titres, the HEM3 strain even showed a 50\% lower specific and volumetric productivity than the benchmark strain. Taken together, it turned out that the trends seen in microscale data could not be seen in the bioreactor. A possible explanation for these diverging findings could be found in the considerably different cultivation conditions. Microscale cultivations may challenge cell growth and productivity by phases of $\mathrm{O}_{2}$ shortage or starvation, whereas a bioreactor provides optimal cultivation conditions.

Considering the complex and so far poorly understood regulation of heme biosynthesis, a multitude of single or combined factors may have either positive or negative effects on this pathway. Thus, additional studies will be required to unravel the regulation of heme biosynthesis, in order to allow non-speculative conclusions. Since our selection of $H E M$ co-overexpression partners was based on trends from microscale cultivations, we cannot exclude, that either of the remaining six HEM genes or combinations thereof might yield more beneficial results than cooverexpressed HEM1 or HEM3 in bioreactor cultivations. Ultimately, in contrast to analogous studies in S. cerevisiae $[9,11]$, metabolic pathway engineering in $P$. pastoris did not prove to be a useful strategy to allow higher titres of recombinant active heme protein, suggesting distinct differences of this pathway between the two yeasts. However, co-overexpression of two or more HEM genes from a library of promoters of varying strengths might still enhance endogenous heme biosynthesis in $P$. pastoris and will be assessed in future studies.

\section{Medium supplementation}

\section{Medium supplementation in microscale cultivations}

We tested ALA, $\mathrm{FeSO}_{4}$ and hemin as medium supplements in microscale cultivations of the benchmark strain. Supplementation with ALA at an excess concentration of $1 \mathrm{mM}$, as reported in literature [22,26,27], did not result in measurably more active product. However, addition of $1 \mathrm{mM} \mathrm{FeSO}_{4}$ boosted the amount of active HRP up to 7-fold (Figure 3), hinting at a potential shortage of iron in heme biosynthesis. Upon supplementation of the minimal medium with different concentrations of hemin, we even measured 18-fold increased HRP activity compared to non-supplemented conditions. We also investigated the effect in case both, $\mathrm{FeSO}_{4}$ and hemin, were supplemented concomitantly and observed that the beneficial effect of $\mathrm{FeSO}_{4}$ became less pronounced with increasing concentrations of hemin (Figure 3). Apparently, as all apo-HRP was readily saturated with cofactor at a hemin concentration of $10 \mu \mathrm{M}$, additional excess of iron did not improve HRP activities any further and the cofactor bottleneck was opened up.

\section{ALA supplementation in the bioreactor}

We performed a comparative cultivation experiment in the bioreactor to confirm the results obtained in microscale cultivations that the commonly used supplement ALA $[22,26,27]$ does not affect the production of a recombinant active heme protein in $P$. pastoris. We cultivated the benchmark strain in parallel dynamic batch cultivations with and without the presence of $1 \mathrm{mM}$ ALA. Table 3 shows that both, strain physiology and productivity, were

Table 2 Strain characteristic physiological parameters determined for the benchmark, HEM1 and HEM3 strain

\begin{tabular}{|c|c|c|c|c|c|c|c|}
\hline Strain & $\begin{array}{l}\Delta \text { time }_{\text {adapt }} \\
{[\mathrm{h}]}\end{array}$ & $\begin{array}{l}\mathrm{Y}_{\mathrm{X} / \mathrm{MeOH}} \\
{[\mathrm{C}-\mathrm{mol} / \mathrm{C}-\mathrm{mol}]}\end{array}$ & $\begin{array}{l}\mathrm{Y}_{\mathrm{CO} 2 / \mathrm{MeOH}} \\
{[\mathrm{C}-\mathrm{mol} / \mathrm{C}-\mathrm{mol}]}\end{array}$ & C-balance & $\begin{array}{l}\mathrm{q}_{\mathrm{MeOH}} \\
{[\mathrm{mmol} / \mathrm{g} / \mathrm{h}]}\end{array}$ & $\begin{array}{l}q_{p} \\
{[U / g / h]}\end{array}$ & $\begin{array}{l}r_{p} \\
{[U / L / h]}\end{array}$ \\
\hline Benchmark & 8.2 & 0.02 & 1.00 & 1.02 & 0.75 & 1.11 & 37.5 \\
\hline HEM1 & 8.2 & 0.04 & 0.94 & 0.98 & 0.69 & 1.10 & 35.9 \\
\hline HEM3 & 7.9 & 0.03 & 0.93 & 0.96 & 0.70 & 0.49 & 17.1 \\
\hline
\end{tabular}

$\Delta$ time $_{\text {adapt }}$ time for adaptation of the culture to methanol; $\mathrm{Y}_{\mathrm{X} / \mathrm{MeOH}}, \mathrm{Y}_{\mathrm{CO} / \mathrm{MeOH}}$, yields of biomass or $\mathrm{CO}_{2}$ per $\mathrm{C}$-mol of substrate methanol; $\mathrm{C}$-balance, sum of $\mathrm{Y}_{\mathrm{X} / \mathrm{MeOH}}$ and $\mathrm{Y}_{\mathrm{CO} / \mathrm{MeOH}}$ which ideally should result in 1.0; $\mathrm{q}_{\mathrm{MeOH}}$, average specific uptake rate of methanol during consecutive methanol pulses; $\mathrm{q}_{\mathrm{p}}$, specific HRP productivity; $r_{p}$, volumetric HRP productivity calculated from the point of induction until the end of cultivation. 


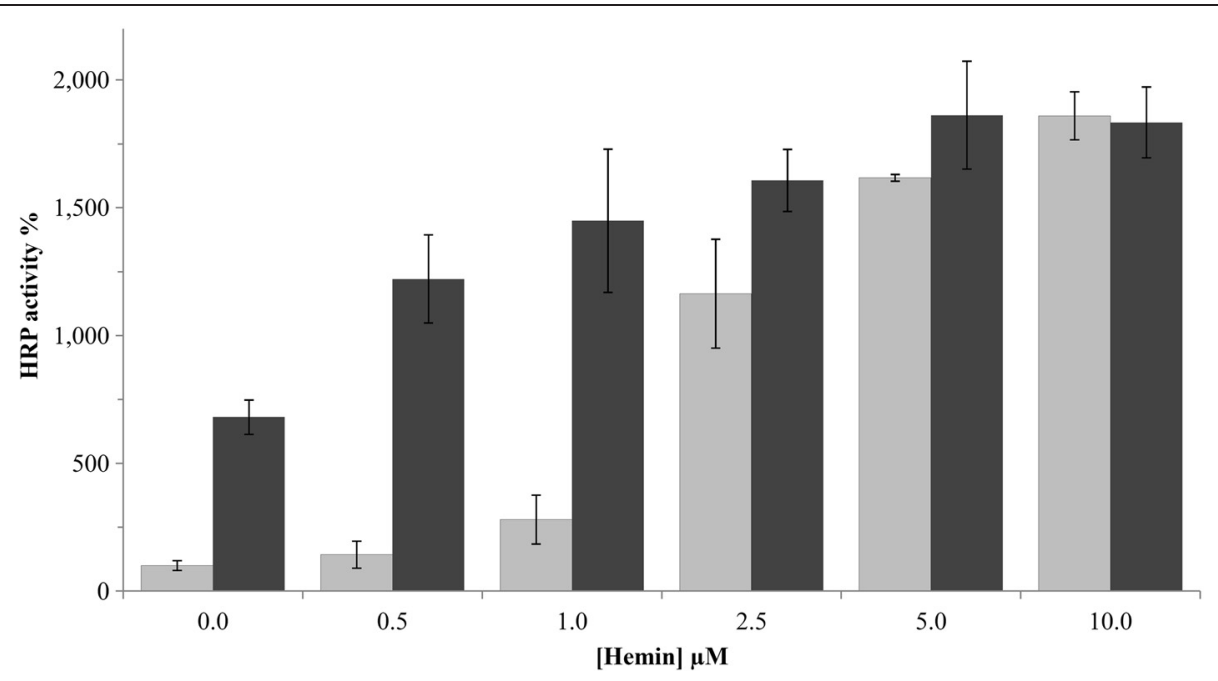

Figure 3 Effect of medium supplementation with $\mathrm{FeSO}_{4}$ and hemin on HRP activity in microscale cultivations. Volumetric HRP activity from minimal medium without supplementation was set to 100\%. Bars are average values \pm SD from independent triplicate cultivations. Light gray, no $\mathrm{FeSO}_{4}$; dark gray, 1 $\mathrm{mM} \mathrm{FeSO}_{4}$.

not affected by the presence of ALA. Since the amount of active HRP was the same for both conditions, we concluded that ALA was not beneficial for the activation of the produced apo-HRP. This observation is different from what was described previously by Morawski et al., where a $32 \%$ increase in HRP activity was measured in the culture supernatant after supplementation with ALA, trace elements and thiamine [17]. Thus, we speculate that the activation effect observed by Morawski et al. was rather caused by the addition of the iron-containing trace element solution than by ALA. Furthermore, our results conclusively showed that the intracellular production of ALA in the heme biosynthesis pathway of $P$. pastoris was not the rate limiting step in contrast to E. coli [10], which is also in agreement with the study of Arrese et al. [28].

\section{Optimization of hemin supplementation in the bioreactor}

Based on the results obtained in microscale cultivations, we supplemented the cultivation broth of three parallel dynamic batch cultivations of the benchmark strain with $0.1,1.0$ or $10.0 \mu \mathrm{M}$ hemin. As shown in Table 4, adaptation time, yields and uptake rates of the benchmark strain were not affected by the presence of hemin. In terms of productivity, both the specific and the volumetric productivity were doubled at a concentration of $10.0 \mu \mathrm{M}$ hemin. Since the total extracellular protein content was comparable in all three cultivations, we concluded that not the productivity of the yeast was altered, but rather that the produced apo-protein was activated posttranslationally by hemin in the cultivation broth. Based on our previous experiences with this expression system $[22,23,29,30]$, we estimated the amount of HRP in the cultivation broth to be $<3 \mu \mathrm{M}$. Thus, we concluded that an excess hemin concentration is required to effectively saturate secreted apo-HRP (Table 4).

\section{Activation studies with hemin}

To prove our hypothesis of a posttranslational conversion of apo-HRP to holo-HRP by hemin, we incubated cellfree, sterile-filtered supernatant from a non-supplemented benchmark cultivation with different concentrations of hemin and analyzed activity over time. As shown in Table 5, already after $5 \mathrm{~min}$ of incubation a concentration dependent activation was observed and after $72 \mathrm{~h}$ of incubation the initial activity was even doubled. Based thereon,

Table 3 Strain specific physiological parameters of the benchmark strain with and without ALA supplementation

\begin{tabular}{|c|c|c|c|c|c|c|c|}
\hline $\begin{array}{l}\text { ALA } \\
{[1 \mathrm{mM}]}\end{array}$ & $\begin{array}{l}\Delta \text { time }_{\text {adapt }} \\
{[\mathrm{h}]}\end{array}$ & $\begin{array}{l}\mathrm{Y}_{\mathrm{X} / \mathrm{MeOH}} \\
{[\mathrm{C}-\mathrm{mol} / \mathrm{C}-\mathrm{mol}]}\end{array}$ & $\begin{array}{l}\mathrm{Y}_{\mathrm{CO} / \mathrm{MeOH}} \\
{[\mathrm{C}-\mathrm{mol} / \mathrm{C}-\mathrm{mol}]}\end{array}$ & C-balance & $\begin{array}{l}\mathrm{q}_{\mathrm{MeOH}} \\
{[\mathrm{mmol} / \mathrm{g} / \mathrm{h}]}\end{array}$ & $\begin{array}{l}q_{p} \\
{[U / g / h]}\end{array}$ & $\begin{array}{l}r_{p} \\
{[U / L / h]}\end{array}$ \\
\hline+ & 8.1 & 0.03 & 0.95 & 0.98 & 0.73 & 1.08 & 36.7 \\
\hline- & 8.2 & 0.04 & 0.94 & 0.98 & 0.76 & 1.09 & 37.2 \\
\hline
\end{tabular}

$\Delta$ time $_{\text {adapt }}$ time for adaptation of the culture to methanol; $\mathrm{Y}_{\mathrm{X} / \mathrm{MeOH}}, \mathrm{Y}_{\mathrm{CO} / \mathrm{MeOH}}$, yields of biomass or $\mathrm{CO}_{2}$ per $\mathrm{C}$-mol of substrate methanol; $\mathrm{C}$-balance, sum of $\mathrm{Y}_{\mathrm{X} / \mathrm{MeOH}}$ and $\mathrm{Y}_{\mathrm{CO} / \mathrm{MeOH}}$ which ideally should result in $1.0 ; \mathrm{q}_{\mathrm{MeOH}}$, average specific uptake rate of methanol during consecutive methanol pulses; $\mathrm{q}_{\mathrm{p}}$, specific HRP productivity; $r_{p}$, volumetric HRP productivity calculated from the point of induction until the end of cultivation. 
Table 4 Strain characteristic physiological parameters determined for the benchmark strain cultivated in hemin-supplemented media

\begin{tabular}{|c|c|c|c|c|c|c|c|}
\hline $\begin{array}{l}\text { Hemin } \\
{[\mu \mathrm{M}]}\end{array}$ & $\begin{array}{l}\Delta \text { time }_{\text {adapt }} \\
{[\mathrm{h}]}\end{array}$ & $\begin{array}{l}\mathrm{Y}_{\mathrm{X} / \mathrm{MeOH}} \\
{[\mathrm{C}-\mathrm{mol} / \mathrm{C}-\mathrm{mol}]}\end{array}$ & $\begin{array}{l}\mathrm{Y}_{\mathrm{CO} / \mathrm{MeOH}} \\
{[\mathrm{C}-\mathrm{mol} / \mathrm{C}-\mathrm{mol}]}\end{array}$ & C-balance & $\begin{array}{l}q_{\mathrm{MeOH}} \\
{[\mathrm{mmol} / \mathrm{g} / \mathrm{h}]}\end{array}$ & $\begin{array}{l}q_{p} \\
{[U / g / h]}\end{array}$ & $\begin{array}{l}r_{p} \\
{[U / L / h]}\end{array}$ \\
\hline 0.1 & 6.5 & 0.04 & 0.89 & 0.93 & 0.69 & 1.10 & 34.3 \\
\hline 1.0 & 6.4 & 0.04 & 0.93 & 0.97 & 0.71 & 1.26 & 36.8 \\
\hline 10.0 & 6.5 & 0.03 & 0.89 & 0.96 & 0.70 & 2.35 & 73.2 \\
\hline
\end{tabular}

$\Delta$ time $_{\text {adapt }}$ time for adaptation of the culture to methanol; $\mathrm{Y}_{\mathrm{X} / \mathrm{MeOH}}, \mathrm{Y}_{\mathrm{CO} / \mathrm{MeOH}}$, yields of biomass or $\mathrm{CO}_{2}$ per $\mathrm{C}$-mol of substrate methanol; $\mathrm{C}$-balance, sum of $\mathrm{Y}_{\mathrm{X} / \mathrm{MeOH}}$ and $\mathrm{Y}_{\mathrm{CO} / \mathrm{MeOH}}$ which ideally should result in 1.0; $\mathrm{q}_{\mathrm{MeOH}}$, average specific uptake rate of methanol during consecutive methanol pulses; $\mathrm{q}_{\mathrm{p}}$, specific $\mathrm{HRP}$ productivity; $r_{p}$, volumetric HRP productivity.

we concluded that hemin should be present in excess to allow effective apo-protein activation.

\section{Conclusions}

In this study we present a systematic approach to optimize heme availability and thus boost the amount of active heme protein produced in the yeast $P$. pastoris by evaluating metabolic pathway engineering and medium supplementation. The results can be summarized as:

- The heme biosynthesis pathway of P. pastoris was analyzed and corresponding genes were identified and annotated in silico.

- In contrast to previous studies, overexpression of single HEM genes did not result in enhanced activity or higher yield of the model heme protein HRP in bioreactor cultivations of recombinant $P$. pastoris strains. However, combinations of HEM genes cooverexpressed from a library of differently regulated promoters might still enhance endogenous heme biosynthesis of $P$. pastoris.

- Medium supplementation with the traditionally used and pricy heme precursor ALA did not increase the yield of active product and can be omitted in future cultivations. $\mathrm{FeSO}_{4}$ and hemin on the other hand turned out to be useful medium supplements to increase the yield of active heme protein.

- Hemin was identified as the most effective supplement. It activated the secreted model heme protein posttranslationally in the cultivation broth and should be added in moderate excess to effectively saturate secreted apo-species of the target protein.

Table 5 Posttranslational activation of apo-HRP with hemin

\begin{tabular}{lll}
\hline $\begin{array}{l}\text { Hemin } \\
{[\boldsymbol{\mu M}]}\end{array}$ & $\begin{array}{l}\text { Specific activity }[\mathbf{U} / \mathbf{m g}] \\
\text { after } \mathbf{5} \text { min of incubation }\end{array}$ & $\begin{array}{l}\text { Specific activity }[\mathbf{U} / \mathbf{m g}] \\
\text { after } \mathbf{7 2} \text { h of incubation }\end{array}$ \\
\hline- & 34.8 & 35.3 \\
1.0 & 42.4 & 67.0 \\
5.0 & 46.8 & 75.4 \\
10.0 & 51.8 & 77.8 \\
\hline
\end{tabular}

Cell-free cultivation supernatant was incubated with the indicated concentrations of hemin and volumetric HRP activity was measured after $5 \mathrm{~min}$ and $72 \mathrm{~h}$.
The results shown in this study present a guideline for the successful recombinant production of active heme protein in the yeast $P$. pastoris and offer an easy-to-do solution to maximize the ratio of holo- over apo-protein resulting in a considerable increase of active target protein.

\section{Methods}

\section{Chemicals}

2,2' -azino-bis(3-ethylbenzthiazoline-6-sulfonic acid) diammonium salt (ABTS), $\mathrm{D}(+)$-biotin and hemin were purchased from Sigma-Aldrich (Austria). Difco ${ }^{\mathrm{Tat}}$ yeast nitrogen base $(\mathrm{YNB})$ w/o amino acids, Bacto $^{\mathrm{Tm}}$ tryptone and Bacto $^{\mathrm{TM}}$ yeast extract were obtained from Becton Dickinson (Austria). Zeocin $^{\mathrm{TM}}$ was obtained from InvivoGen (France). Other chemicals were obtained from Carl Roth (Germany).

\section{Pichia pastoris strains}

All strains in this study were based on the P. pastoris wildtype strain CBS 7435 (identical to NRRL Y-11430 and ATCC 76273). The Mut ${ }^{\mathrm{S}}$ phenotype has been found previously to be superior over the $\mathrm{Mut}^{+}$phenotype for recombinant HRP production in terms of volumetric productivity and production efficiency [24]. Hence, an aox 1 deletion strain (PpMutS) was used as starting strain [31]. Homologs of the HEM genes of $S$. cerevisiae were identified by BLAST searches [32] in the published genome sequence of $P$. pastoris CBS 7435 [18] and the sequences were verified by Sanger sequencing (Microsynth, Austria). Sequence identities of the HEM gene products from S. cerevisiae and P. pastoris were determined on the LALIGN server.

The HRP expression construct was based on the pPpT4 Alpha_S vector [31] where HRP C1A expression was under control of the promoter of the AOX1 gene (PAOX1). Transformants were identified by Zeocin ${ }^{\mathrm{TM}}$ resistance. The S. cerevisiae MAT $\alpha$ prepro signal peptide facilitated HRP secretion. All HEM co-overexpression constructs were based on the plasmid pPpKan_S [32], harboring a kanamycin resistance gene for selection and the strongly methanol-inducible PAOX1 for gene expression. Also, the promoters PGAP and PCAT1 [Vogl et al., manuscript in preparation] were tested for co-overexpression. Transformation of the HRP expression cassette to PpMutS and 
of the co-overexpression constructs to the PpMutS-based HRP production strain (called benchmark strain) was performed as described previously [24]. All eight HEM genes of the heme biosynthesis pathway were co-overexpressed separately and their influence on HRP production was studied by cultivation of approximately 80 transformants per co-overexpression construct in 96-deep well plates (DWP). As negative co-overexpression control, eGFP was co-overexpressed with HRP. The copy number of the HRP gene in selected strains was determined by quantitative real-time PCR according to a previous protocol [33] and as described recently [24].

\section{Microscale cultivations in 96-deep well plates}

Microscale cultivations in 96-DWPs were performed similar to [34]: Strains were grown in $250 \mu \mathrm{L}$ BMD1\% $(11 \mathrm{~g} / \mathrm{L}$ alpha-D(+)-glucose monohydrate, $13.4 \mathrm{~g} / \mathrm{L} \mathrm{YNB}, 0.4 \mathrm{mg} / \mathrm{L}$ $\mathrm{D}(+)$-biotin, $0.1 \mathrm{M}$ potassium phosphate buffer, $\mathrm{pH} 6.0$ ) at $28^{\circ} \mathrm{C}, 320 \mathrm{rpm}, 80 \%$ humidity. After approximately $60 \mathrm{~h}$, an induction pulse of $250 \mu \mathrm{L}$ BMM2 (1\% (v/v) methanol, $13.4 \mathrm{~g} / \mathrm{L} \mathrm{YNB}, 0.4 \mathrm{mg} / \mathrm{L} \mathrm{D}(+)$-biotin, $0.1 \mathrm{M}$ potassium phosphate buffer, $\mathrm{pH}$ 6.0) was added, followed by three pulses of $50 \mu \mathrm{L}$ BMM10 (5\% (v/v) methanol, 13.4 g/L YNB, 0.4 mg/L D(+)-biotin, 0.1 $\mathrm{M}$ potassium phosphate buffer, pH 6.0) per well 12, 24 and $36 \mathrm{~h}$ after the first pulse. HRP activity was determined by mixing $15 \mu \mathrm{L}$ supernatant with $140 \mu \mathrm{L}$ assay solution ( $1 \mathrm{mM}$ ABTS, $0.9 \mathrm{mM} \mathrm{H}_{2} \mathrm{O}_{2}$, $50 \mathrm{mM}$ sodium acetate, $\mathrm{pH} 4.5)$ in a microtiter plate and following the increase in absorbance at $405 \mathrm{~nm}$ on a Spectramax Plus 384 platereader (MolecularDevices, Germany) at room temperature. Medium supplementation studies were performed by additions of ALA, $\mathrm{FeSO}_{4}$ and hemin to BMD1\% from a $100 \mathrm{mM}$ ALA stock, a $100 \mathrm{mM} \mathrm{FeSO}$, stock and a $500 \mu \mathrm{M}$ hemin stock (in $10 \mathrm{mM} \mathrm{KOH}$ ), respectively.

\section{Bioreactor cultivations Preculture}

Precultures were grown in YNB medium $(0.1 \mathrm{M}$ potassium phosphate buffer, $\mathrm{pH}$ 6.0; 3.4 g/L YNB w/o amino acids and ammonium sulfate; $10 \mathrm{~g} / \mathrm{L}\left(\mathrm{NH}_{4}\right)_{2} \mathrm{SO}_{4} ; 400 \mathrm{mg} / \mathrm{L}$ biotin; $20 \mathrm{~g} / \mathrm{L}$ glucose) in $1 \mathrm{~L}$ shake flasks at $30^{\circ} \mathrm{C}$ and $230 \mathrm{rpm}$ for $24 \mathrm{~h}$.

\section{Dynamic batch cultivations}

For dynamic batch cultivations, $1.8 \mathrm{~L}$ of double concentrated basal salt medium (BSM; $26.7 \mathrm{~mL} / \mathrm{L}$ 85\% phosphoric acid; $1.17 \mathrm{~g} / \mathrm{L} \quad \mathrm{CaSO}_{4} \cdot 2 \mathrm{H}_{2} \mathrm{O} ; 18.2 \mathrm{~g} / \mathrm{L} \mathrm{K}_{2} \mathrm{SO}_{4} ; 14.9 \mathrm{~g} / \mathrm{L}$ $\mathrm{MgSO}_{4} \cdot 7 \mathrm{H}_{2} \mathrm{O} ; 4.13 \mathrm{~g} / \mathrm{L} \mathrm{KOH} ; 0.3 \mathrm{~mL} / \mathrm{L}$ Antifoam Struktol J650; $60 \mathrm{~g} / \mathrm{L}$ glycerol) were sterilized in $3 \mathrm{~L}$ bioreactor vessels (DR03F; DASGIP, Switzerland). After sterilization, $4.35 \mathrm{~mL} / \mathrm{L}$ trace element solution (PTM1; $6.0 \mathrm{~g} / \mathrm{L} \mathrm{CuSO}{ }_{4} \cdot 5 \mathrm{H}_{2} \mathrm{O} ; 0.08 \mathrm{~g} / \mathrm{L} \mathrm{NaI} ; 3.0 \mathrm{~g} / \mathrm{L} \mathrm{MnSO}_{4}$. $\mathrm{H}_{2} \mathrm{O} ; 0.2 \mathrm{~g} / \mathrm{L} \mathrm{Na} \mathrm{NoO}_{4} \cdot 2 \mathrm{H}_{2} \mathrm{O} ; 0.02 \mathrm{~g} / \mathrm{L} \mathrm{H}_{3} \mathrm{BO}_{3} ; 0.5 \mathrm{~g} / \mathrm{L}$
$\mathrm{CoCl}_{2} ; 20.0 \mathrm{~g} / \mathrm{L} \mathrm{ZnCl} ; 65.0 \mathrm{~g} / \mathrm{L} \mathrm{FeSO}_{4} \cdot 7 \mathrm{H}_{2} \mathrm{O} ; 0.2 \mathrm{~g} / \mathrm{L}$ biotin; $5 \mathrm{~mL} / \mathrm{L} \mathrm{H}_{2} \mathrm{SO}_{4}$ ) were added and $\mathrm{pH}$ was set to 5.0 with concentrated ammonia solution. The precultures were transferred aseptically to the respective vessel (the inoculation volume was $10 \%$ ) and a batch phase on glycerol was carried out at $30^{\circ} \mathrm{C}$ with the stirrer fixed at $900 \mathrm{rpm}$. Aeration with compressed dry air was set to $1 \mathrm{vvm}$. Dissolved oxygen $\left(\mathrm{dO}_{2}\right)$ was measured with a sterilizable VisiFerm DO 225 probe (Hamilton, Switzerland) and controlled to be higher than $20 \%$. The $\mathrm{pH}$ was measured with a sterilizable electrode (Mettler Toledo, Switzerland) and maintained constant at $\mathrm{pH}$ 5.0. Reactor weight was continuously recorded by a precision balance (Sartorius, Germany). Following complete glycerol consumption as indicated by an increase in the offgas signal, temperature was lowered to $25^{\circ} \mathrm{C}$ and an adaptation pulse of $0.5 \%(\mathrm{v} / \mathrm{v})$ methanol (containing $4.35 \mathrm{~mL} / \mathrm{L}$ PTM1) was added. After adaptation, $1.0 \%(\mathrm{v} / \mathrm{v})$ methanol was pulsed repeatedly (for an example see Additional file 4). Before and after each pulse samples were taken and analyzed for $\mathrm{OD}_{600}$, dry cell weight, HRP activity, extracellular protein content and methanol concentration.

\section{Analysis of growth and expression parameters}

Dry cell weight (DCW) was determined by centrifugation of $5 \mathrm{~mL}$ fermentation broth ( $4500 \mathrm{rpm}, 10 \mathrm{~min}, 4^{\circ} \mathrm{C}$ ), washing the pellet with $5 \mathrm{~mL}$ water and subsequent drying to a constant weight at $105^{\circ} \mathrm{C}$. HRP activity in the cell-free supernatant was determined using a previously described assay [23] in a CuBiAn-XC enzymatic robot (OptoCell, Germany). Protein concentration was determined using a Bradford protein assay kit (Thermo Scientific, USA). All growth and protein expression parameters were determined in duplicates.

\section{Analysis of substrate concentration}

Methanol concentration in the cell-free supernatant was determined by HPLC as described previously [22]. Glycerol concentration was measured from cell-free samples in the $\mathrm{CuBiAn-XC}$ enzymatic robot. The device was calibrated with water-diluted glycerol standards ranging from 0 to $0.25 \mathrm{~g} / \mathrm{L}$. Samples with higher glycerol concentrations were automatically diluted by the system.

\section{Calculation of strain physiological characteristics}

Physiologically relevant parameters for characterization of the different yeast strains cultivated at different conditions and for quantification of the bioprocess were: Carbon dioxide evolution rate (CER; $\mathrm{mmol} / \mathrm{L} / \mathrm{h})$, biomass yield $\left(\mathrm{Y}_{\mathrm{X} / \mathrm{MeOH}} ; \mathrm{C}-\mathrm{mol} / \mathrm{C}-\mathrm{mol}\right)$, carbon dioxide yield ( $\mathrm{Y}_{\mathrm{CO} 2 / \mathrm{MeOH}}$; C-mol/C-mol), C-balance, specific methanol uptake rate $\left(\mathrm{q}_{\mathrm{MeOH}} ; \mathrm{mmol} / \mathrm{g} / \mathrm{h}\right)$, specific productivity $\left(\mathrm{q}_{\mathrm{p}} ; \mathrm{U} / \mathrm{g} / \mathrm{h}\right)$, volumetric productivity $\left(\mathrm{r}_{\mathrm{p}} ; \mathrm{U} / \mathrm{L} / \mathrm{h}\right)$, specific activity $(\mathrm{U} / \mathrm{mg})$. All details on the calculation of these parameters have been published previously [34]. 


\section{Additional files}

\section{Additional file 1: Pichia pastoris CBS 7435 HEM open reading frames. The single nucleotide polymorphism of HEM15, T918, is marked in grey.}

Additional file 2: Co-overexpression of eGFP from PAOX1. The principial applicability of the employed co-overexpression construct is demonstrated indirectly by eGFP fluorescence of the strains co-overexpressing HRP and eGFP. The first two bars represent the starting strain, PpMutS, and the benchmark strain as controls. Fluorescence was determined at ex/em 488/507 nm, and normalized to the OD600 to account for potential growth differences.

\section{Additional file 3: Co-overexpressions of HRP with either HEM1 or} HEM3 from either PAOX1 or PCAT1. 1, cO-overexpression of HEM1 or HEM3 from PAOX1; 2, co-overexpression of HEM1 or HEM3 from PCAT1. White bars, eGFP co-overexpression control; black bars, HEM1 cooverexpression; gray bars, HEM3 co-overexpression. The benchmark strain was included in all cultivations and set to $100 \%$ as reference (first bars).

Additional file 4: Batch cultivations of three recombinant $P$. pastoris strains. 1, benchmark strain; 2, HEM1 strain; 3, HEM3 strain; a/c/e, CER signal (solid line) and specific methanol uptake rate (open circles); b/d/f, carbon dioxide yields ( $\mathrm{Y}_{\mathrm{CO} 2 / \mathrm{s}}$; grey squares) and biomass yields ( $\mathrm{Y}_{\mathrm{X} / \mathrm{s} \text {; }}$ black circles)

\section{Abbreviations}

ABTS: 2,2"-azino-bis(3-ethylbenzthiazoline-6-sulfonic acid) diammonium salt; ALA: 5-aminolevulinic acid; AOX1: Alcohol oxidase 1 gene; CER: Carbon evolution rate; 96-DWP: 96-deep well plate; eGFP: Enhanced green fluorescent protein; HRP: Horseradish peroxidase; YNB: DifCo ${ }^{T M}$ yeast nitrogen base.

\section{Competing interests}

The authors declare that they have no competing interests.

\section{Authors' contributions}

FWK, SC, TV and OS designed the experiments, analyzed and interpreted the data. FWK, SC, MJ, MGE and TV performed the experiments. FWK, SC and OS wrote the manuscript. FWK, AG, CH and OS conceived of the study. AG, CH and OS supervised the research. All authors read and approved the final manuscript.

\section{Authors' information}

FWK, TV, MGE, AG: Graz University of Technology, Institute of Molecular Biotechnology, NAWI Graz, Petersgasse 14, 8010 Graz, Austria. SC, MJ, CH, OS: Vienna University of Technology, Institute of Chemical Engineering, Research Area Biochemical Engineering, Gumpendorfer Strasse 1a, 1060 Vienna, Austria.

\section{Acknowledgements}

The authors would like to acknowledge support from NAWI Graz and the Austrian Science Fund FWF (projects: P24861-B19 and W901 DK Molecular Enzymology). This research was also funded by the European Union's Seventh Framework Programme (FP7/2007-2013) under grant agreement N²66025 (http://bionexgen-fp7.eu).

\section{Author details}

${ }^{1}$ Graz University of Technology, NAWI Graz, Institute of Molecular Biotechnology, Graz, Austria. ${ }^{2}$ Vienna University of Technology, Institute of Chemical Engineering, Research Area Biochemical Engineering, Gumpendorfer Strasse 1a, 1060 Vienna, Austria.

Received: 29 October 2014 Accepted: 26 December 2014 Published online: 13 January 2015

\section{References}

1. Franken ACW, Lokman BC, Ram AFJ, Punt PJ, van den Hondel CAMJJ, De Weert $\mathrm{S}$. Heme biosynthesis and its regulation: towards understanding and improvement of heme biosynthesis in filamentous fungi. Appl Microbiol Biotechnol. 2011;91:447-60.
2. Heinemann IU, Jahn M, Jahn D. The biochemistry of heme biosynthesis. Arch Biochem Biophys. 2008;474:238-51.

3. Layer G, Reichelt J, Jahn D, Heinz DW. Structure and function of enzymes in heme biosynthesis. Prot Sci. 2010;19:1137-61.

4. Franken ACW, Lokman BC, Ram AFJ, van den Hondel CAMJJ, de Weert S, Punt PJ. Analysis of the role of the Aspergillus niger aminolevulinic acid synthase (hemA) gene illustrates the difference between regulation of yeast and fungal haem- and sirohaem-dependent pathways. Fems Microbiol Lett. 2012;335:104-12

5. Franken ACW, Werner ER, Haas H, Lokman BC, van den Hondel CAMJJ, Ram AFJ, et al. The role of coproporphyrinogen III oxidase and ferrochelatase genes in heme biosynthesis and regulation in Aspergillus niger. Appl Microbiol Biotechnol. 2013;97:9773-85.

6. Li FF, Wang Y, Gong K, Wang Q, Liang QF, Qi QS. Constitutive expression of RyhB regulates the heme biosynthesis pathway and increases the 5 -aminolevulinic acid accumulation in Escherichia coli. Fems Microbiol Lett. 2014;350:209-15.

7. Hoffman M, Gora M, Rytka J. Identification of rate-limiting steps in yeast heme biosynthesis. Biochem Biophys Res Comm. 2003;310:1247-53.

8. Martínez JL, Liu L, Petranovic D, Nielsen J. Engineering the oxygen sensing regulation results in an enhanced recombinant human hemoglobin production by Saccharomyces cerevisiae. Biotechnol Bioeng. 2015;1:181-8.

9. Michener JK, Nielsen J, Smolke CD. Identification and treatment of heme depletion attributed to overexpression of a lineage of evolved P450 monooxygenases. Proc Natl Acad Sci U S A. 2012;109:19504-9.

10. Woodard SI, Dailey HA. Regulation of heme-biosynthesis in Escherichia coli. Arch Biochem Biophys. 1995;316:110-5.

11. Liu LF, Martinez JL, Liu ZH, Petranovic D, Nielsen J. Balanced globin protein expression and heme biosynthesis improve production of human hemoglobin in Saccharomyces cerevisiae. Metab Eng. 2014;21:9-16.

12. Krishnamurthy $P, X i e T$, Schuetz JD. The role of transporters in cellular heme and porphyrin homeostasis. Pharmacol Ther. 2007;114:345-58.

13. Nishimoto M, Clark JE, Masters BSS. Cytochrome-P450-4a4 - expression in Escherichia coli, purification, and characterization of catalytic properties. Biochem. 1993;32:8863-70.

14. Conesa A, van den Hondel CAMJJ, Punt PJ. Studies on the production of fungal peroxidases in Aspergillus niger. Appl Environ Microbiol. 2000;66:3016-23.

15. Varnado CL, Goodwin DC. System for the expression of recombinant hemoproteins in Escherichia coli. Prot Expr Purif. 2004;35:76-83.

16. Segura MD, Levin G, Miranda MV, Mendive FM, Targovnik HM, Cascone O. High-level expression and purification of recombinant horseradish peroxidase isozyme C in SF-9 insect cell culture. Process Biochem. 2005:40:795-800.

17. Morawski B, Lin ZL, Cirino PC, Joo H, Bandara G, Arnold FH. Functional expression of horseradish peroxidase in Saccharomyces cerevisiae and Pichia pastoris. Protein Eng. 2000;13:377-84.

18. Kueberl A, Schneider J, Thallinger GG, Anderl I, Wibberg D, Hajek T, et al. High-quality genome sequence of Pichia pastoris CBS7435. J Biotechnol. 2011;154:312-20.

19. Tatusov RL, Fedorova ND, Jackson JD, Jacobs AR, Kiryutin B, Koonin EV, et al. The COG database: an updated version includes eukaryotes. BMC Bioinformatics. 2003:4:41.

20. Vogl T, Glieder A. Regulation of Pichia pastoris promoters and its consequences for protein production. N Biotechnol. 2013;30:385-404.

21. Cregg JM, Tolstorukov I, Kusari A, Sunga J, Madden K, Chappell T. Expression in the yeast Pichia pastoris. Methods Enzymol. 2009;463:169-89.

22. Dietzsch C, Spadiut O, Herwig C. A fast approach to determine a fed batch feeding profile for recombinant Pichia pastoris strains. Microb Cell Fact. 2011;10:85.

23. Dietzsch C, Spadiut O, Herwig C. A dynamic method based on the specific substrate uptake rate to set up a feeding strategy for Pichia pastoris. Microb Cell Fact. 2011;10:14.

24. Krainer FW, Dietzsch C, Hajek T, Herwig C, Spadiut O, Glieder A. Recombinant protein expression in Pichia pastoris strains with an engineered methanol utilization pathway. Microb Cell Fact. 2012;11:22.

25. Capone S, Pletzenauer R, Maresch D, Metzger K, Altmann F, Herwig C, et al. Glyco-variant library of the versatile enzyme horseradish peroxidase. Glycobiol. 2014;24:852-63.

26. Jiang $H$, Morgan JA. Optimization of an in vivo plant P450 monooxygenase system in Saccharomyces cerevisiae. Biotechnol Bioeng. 2004;85:130-7.

27. Morawski B, Quan S, Arnold FH. Functional expression and stabilization of horseradish peroxidase by directed evolution in Saccharomyces cerevisiae. Biotechnol Bioeng. 2001;76:99-107. 
28. Arrese M, Carvajal E, Robison S, Sambunaris A, Panek A, Mattoon J. Cloning of the delta-aminolevulinic acid synthase structural gene in yeast. Curr Genet. 1983;7:175-83.

29. Spadiut O, Dietzsch C, Herwig C. Determination of a dynamic feeding strategy for recombinant Pichia pastoris strains. Methods Mol Biol. 2014:1152:185-94.

30. Spadiut O, Zalai D, Dietzsch C, Herwig C. Quantitative comparison of dynamic physiological feeding profiles for recombinant protein production with Pichia pastoris. Bioprocess Biosyst Eng. 2013. doi:10.1007/s00449-0131087-z.

31. Näätsaari L, Mistlberger B, Ruth C, Hajek T, Hartner FS, Glieder A. Deletion of the Pichia pastoris KU70 homologue facilitates platform strain generation for gene expression and synthetic biology. PLoS One. 2012;7:e39720.

32. Altschul SF, Gish W, Miller W, Myers EW, Lipman DJ. Basic local alignment search tool. J Mol Biol. 1990;215:403-10.

33. Abad S, Kitz K, Hormann A, Schreiner U, Hartner FS, Glieder A. Real-time PCR-based determination of gene copy numbers in Pichia pastoris. Biotechnol J. 2010:5:413-20

34. Weis R, Luiten R, Skranc W, Schwab H, Wubbolts M, Glieder A. Reliable high-throughput screening with Pichia pastoris by limiting yeast cell death phenomena. Fems Yeast Res. 2004;5:179-89.

\section{Submit your next manuscript to BioMed Central and take full advantage of:}

- Convenient online submission

- Thorough peer review

- No space constraints or color figure charges

- Immediate publication on acceptance

- Inclusion in PubMed, CAS, Scopus and Google Scholar

- Research which is freely available for redistribution 